\title{
Ronald G. Douglas: A Master in the Art of Transcending Problems
}

\section{Guoliang Yu, Roger Howe, and Shana Hutchins}

Ronald G. Douglas, pioneering researcher and scholar in the areas of operator algebras and operator theory as well as distinguished professor of mathematics and former executive vice president and provost of Texas A\&M University, passed away February 27, 2018, at the age of 79.

Born in 1938 in Osgood, Indiana, Douglas earned his doctorate in mathematics at Louisiana State University in 1962. He was a professor of mathematics at the University of Michigan until 1969, when he moved to the State University of New York at Stony Brook, where he was a professor of mathematics and later vice provost in 1990. Douglas remained at SUNY at Stony Brook until he came to Texas A\&M in 1996 as executive vice president and provost and a tenured professor in mathematics. He was appointed as a distinguished professor of mathematics at Texas A\&M in 1999 and remained active in research and graduate student mentorship until the time of his death. He also held visiting professor positions in Sweden, Israel, England, and Australia.

Guoliang $\mathrm{Yu}$ is a university distinguished professor of mathematics and inaugural holder of the Thomas W. Powell Chair in Mathematics at Texas A\&M University. His email address is guo 1 iangyu@math . tamu . edu.

Roger E. Howe is the Curtis D. Roberts Professor of Mathematics Education in the Department of Teaching, Learning and Culture with a joint appointment in the Department of Mathematics at Texas A\&M University. $\mathrm{He}$ is also a university distinguished professor and a Permanent Faculty Fellow in the Hagler Institute for Advanced Study. His email address is rogerhowe@tamu.edu.

Shana K. Hutchins is communications manager in the College of Science at Texas A\&M University. Her email address is shutchins@tamu.edu.

For permission to reprint this article, please contact: reprint-permission aams.org.

Communicated by Della Dumbaugh.

DOI: https://dx.doi.org/10.1090/noti 1970

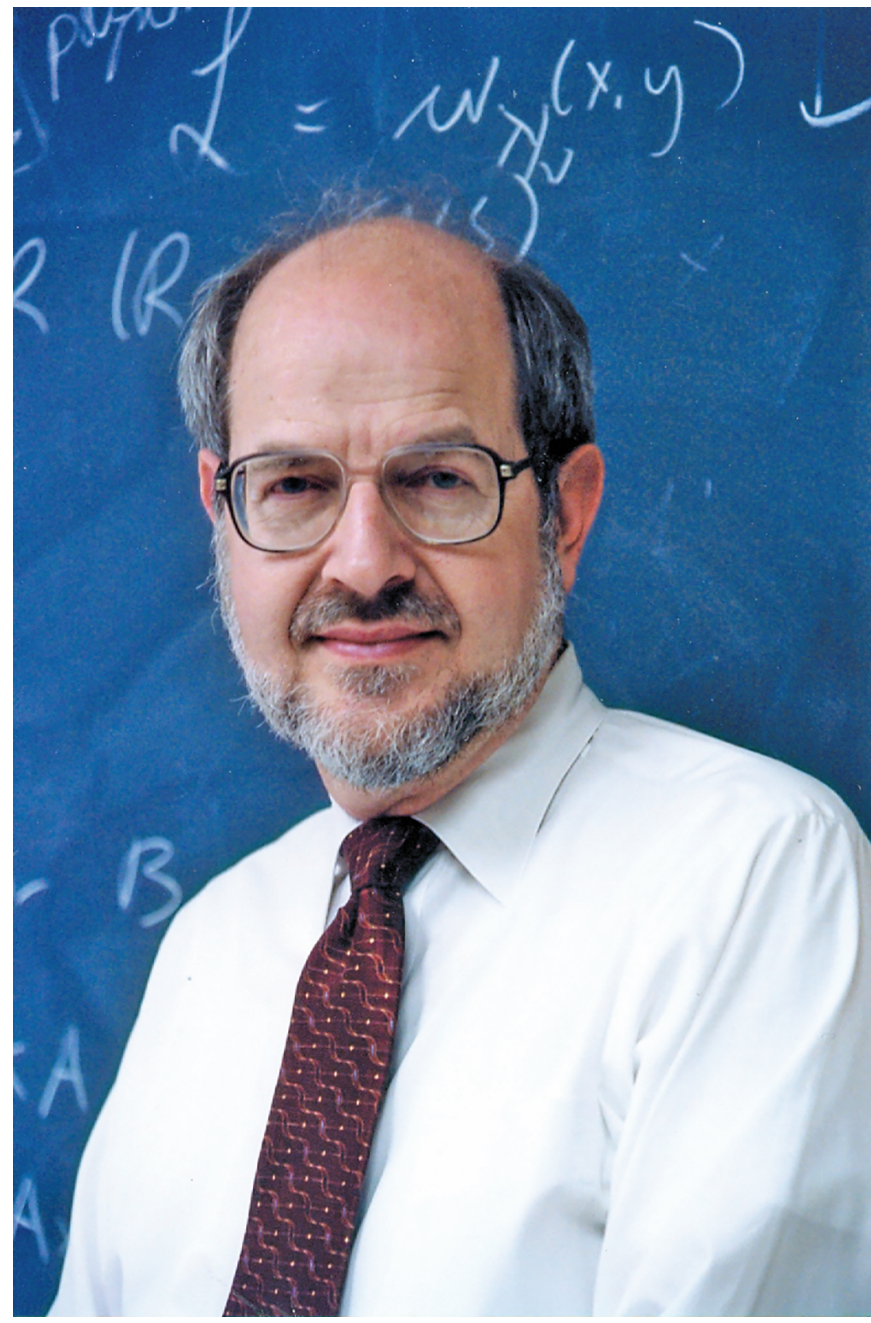

Figure 1. Douglas was appointed as a distinguished professor of mathematics, Texas A\&M University's highest faculty rank, in 1999. 
Douglas served as executive vice president and provost at Texas A\&M from 1996 until 2002, establishing Texas A\&M as a national leader in the number of doctorates awarded to minorities in mathematics, the physical sciences, and engineering. One of his main priorities as Texas A\&M's top academic officer was recruiting additional students to the university's campuses in STEM-related areas, which he saw as vital to an increasingly technology-oriented global economy. Douglas's global vision proved central to another of his crowning achievements as a provost: the creation of Texas A\&M's branch campus in Qatar, which opened its doors in the fall of 2003, offering four engineering degrees and featuring plans for two future research centers that would provide related opportunities for faculty and graduate students. He also championed Texas A\&M's admission into the Association of American Universities, its authorization for a Phi Beta Kappa Chapter, and the creation of its Blinn Team Program, which has become widely respected throughout public higher education as an innovative and unique way to encourage transfer students.

Douglas's research, which focused primarily on operator theory and both Banach and $\mathrm{C}^{*}$-algebras, was nothing short of revolutionary. One of his major contributions to mathematics is the BDF theory of $\mathrm{C}^{*}$-algebra extensions, named in tribute to the researchers who collaborated with Douglas to develop it-Lawrence Brown and Peter Fillmore [1]. In addition to solving the long-standing problem of classifying essentially normal operators, the BDF theory created a novel concept of its own-a new $K$-homology theory that solved an open problem of Atiyah and has since become a cornerstone of a new mathematical area called noncommutative geometry. Apart from BDF theory, two other influential theories bear Douglas's name: Douglas algebras and Cowen-Douglas operators. His four books-including Banach Algebra Techniques in Operator Theory [2]-are considered classics that have helped to define new paradigms in the field $[2,3]$. Likewise, some of his seminal papers have spawned new areas of research actively pursued by current researchers, including dozens of graduate and doctoral students he mentored who are now leaders in their fields.

Beyond his considerable academic and administrative acumen, Douglas also was active on the national education policy and reform scene. He is considered the father of what came to be known as the calculus reform movement during the late 1980s. As then-chairman of the Department of Mathematics at SUNY at Stony Brook, he began researching methods to change the way calculus was taught, given that as many as 40 percent of undergraduates taking introductory calculus at the time were failing it. In addition to organizing the Calculus for a New Century meeting held in Washington, DC, in 1987, Douglas served on a number of committees whose aim was to make calculus more relevant, particularly for non-mathematics majors, by creating introductory calculus courses more in line with the students' needs. He led a National Research Council study of doctoral education in the mathematical sciences in 1991 and also published a series of articles on mathematical education and its relationship to science education as a whole.

Douglas was honored in 2012 as an inaugural Fellow of the American Mathematical Society. In addition, he was a Fellow of the American Association for the Advancement of Science (1989), as well as a National Research Council Fellow at Princeton University's Institute for Advanced Study (1965-66), a Sloan Fellow (1968-74), and a Guggenheim Fellow (1980-81). He also was an invited speaker at the International Congress of Mathematicians 1978 in Helsinki.

In December 2014, Texas A\&M Mathematics honored Douglas by establishing the R. G. Douglas Lectures, which each year brings to campus distinguished mathematicians who work in areas similar to those pioneered by Douglas. Fellow Texas A\&M mathematicians and lifelong friends Carl Pearcy and Ciprian Foiaş made the lead gifts to create the lectureship, perhaps inspired by Douglas's and Pearcy's contributions which were instrumental in establishing the Foiass Lectures earlier that same year.

This past year, Douglas was memorialized at the 2018 International Workshop on Operator Theory and Applications (IWOTA), held July 23-27 on the North Zhongshan campus of East China Normal University in Shanghai. His mathematical descendants and influence span not only his son, Michael R. Douglas, but also generations across the globe, as evidenced by his impact in vast swaths of China and India, in addition to other countries, institutions, and cultures worldwide. 


\section{Paul Baum ${ }^{1}$}

At the 1978 International Congress of Mathematics (ICM) in Helsinki, Ron gave a talk about the Brown-Douglas-Fillmore work on $K$-homology. BDF had discovered how to define $K$-homology via functional analysis and had then used their result to solve the problem of when (modulo compact operators) essentially normal operators are unitarily equivalent.

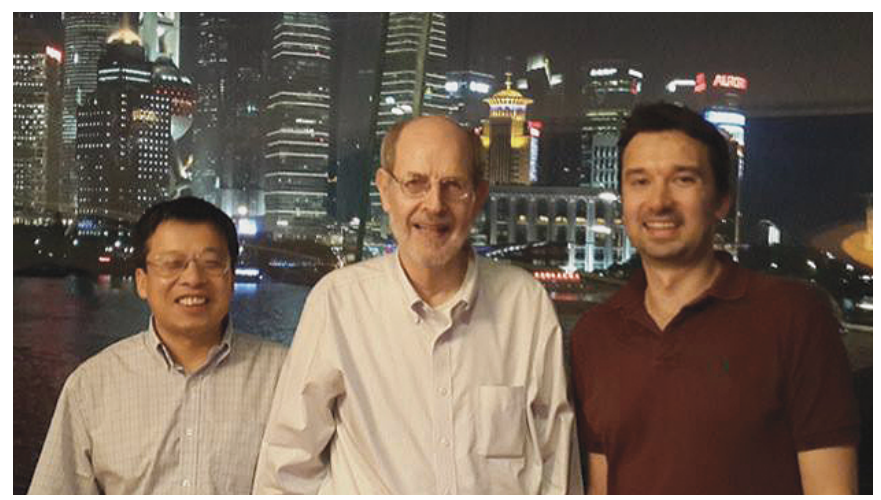

Figure 3. Douglas (center) pictured with Guoliang Yu (left) and Piotr Nowak (right) in Shanghai. Nowak, now a professor in Warsaw, is a former PhD student of Yu, who himself is a former PhD student of Douglas.

Meanwhile, I had been struggling for several years to find a definition of $K$-homology via topological ideas, such as bordism. After many attempts and a lot of nonsense, somewhere in 1978, I was convinced that I had a really good definition of $K$-homology as a group of geometric cycles. In the fall of 1978, letters between Ron and me crossed in the mail, and we began to work to reconcile the two definitions. Sometimes I would go to Stony Brook, and sometimes Ron would come to Providence. In retrospect, it seems obvious how to reconcile the two definitions. The Dirac operator of a Spin-c manifold determines a map from the geometric cycle group to the BDF group.

At the time, however, it was not at all obvious. Each time I went to Stony Brook, Ron and I would work together all day, and in the evening we would go to the Napoleon restaurant in Port Jefferson to feast on rack of lamb. I remember quipping to Ron, "We are keeping this place in business." Sure enough, when Ron and I completed our project and stopped working together, the Napoleon restaurant went out of business.

Decades later, Erik van Erp and I used the isomorphism of the geometric cycle group to the BDF group (what is now called the BDF theory) to solve the index problem for a naturally arising class of differential operators that are Fredholm but not elliptic.

\footnotetext{
${ }_{1}^{1}$ Paul Frank Baum is the Evan Pugh University Professor in Mathematics and a distinguished professor of mathematics at Pennsylvania State University. His email address is pxb6@psu.edu.
}

Over a long period of time, I have enjoyed many discussions with Ron on a great variety of topics. When it came to politics, I would often come away from the conversation with the feeling that Ron's opinions were moderate and reasonable and my opinions were on the far side. Ron was by nature a moderate. At a meeting in College Station in honor of Ron, I offered a toast, saying, "Ron Douglas is one of the best and most interesting people I have known on this planet." I still feel this way.

\section{Ray M. Bowen²}

Dr. Ronald G. Douglas was a distinguished mathematician. Texas A\&M University was fortunate when he agreed to become our executive vice president and provost in 1996. His eminence as a mathematician is reflected in his recognition as a distinguished professor shortly after coming to Texas A\&M University, where a faculty committee of existing distinguished professors selects their future membership. His selection, as an administrator, was a unique event for our university and a tribute to him.

Upon his arrival, we soon learned that his earlier service as a departmental chairman, as a dean, and as a vice provost would serve him well as our provost. His impacts were significant. His academic reputation gave him instant credibility with our faculty. His experience as an academic administrator caused our academic deans and other administrators to quickly respond to his leadership.

He made significant long-term contributions to the academic quality of our university-contributions that contribute in a meaningful way to Texas A\&M today. A few of the many examples are as follows:

- A program with a nearby community college that created a hybrid form of dual enrollment as a pathway into undergraduate enrollment at Texas A\&M.

- A commitment that led to the creation of the highly successful Texas A\&M campus in Qatar.

- A decision to create a Department of Performance Studies that gave visibility to important programs in music and theater.

- Early decisions that established the direction of the then-new Bush School of Government and Public Service. Today, this still rather young school is recognized nationally and internationally for the quality of its programs.

- During his six years as executive vice president and provost, he identified and hired eight of our ten academic deans, deans who continued their contributions long after his service as provost.

It was during his time as executive vice president and provost that Texas A\&M University achieved its long-term

\footnotetext{
${ }^{2}$ Ray M. Bowen is a president emeritus, professor emeritus of mechanical engineering, and 1958 mechanical engineering graduate of Texas A\&M University. His email address is rbowen@tamu.edu.
} 
ambition of being admitted to the Association of American Universities. This admission was not caused by a single person or a single decision. It was the cumulative result of years of growth of a good university. However, the presence of a distinguished mathematician as our academic leader made evident the university's continuing commitment to and fulfillment of its academic goals. Dr. Douglas was a visible symbol of both.

While serving as executive vice president and provost, Dr. Douglas maintained an active program of research in his area of mathematics. Upon completion of his six years in the administration, he joined our mathematics faculty and increased an already significant research program. He especially enjoyed his time in the classroom, as well as his time working with his several PhD students. He continued this phase of his academic career until he passed away in February 2018.

Throughout his long academic career, Dr. Ronald Douglas made major scholarly contributions through his research; made Texas A\&M University and other universities stronger; enhanced the careers of his students and his colleagues; and led an exemplary life as a husband, father, colleague, and friend. Texas A\&M University is fortunate to have been a beneficiary of his distinguished career.

\section{Larry Brown ${ }^{3}$}

Ron was a mentor to me in more than one way early in my career. Working with Ron and Peter Fillmore was one of my best mathematical experiences. This joint work began when I arrived in Stony Brook in 1971, but Ron and Peter had already been working together before. The initial problem had been to classify bounded operators $T$ on a Hilbert space, such that $T^{*} T-T T^{*}$ is compact, up to compact perturbation and unitary equivalence. Ron and Peter already knew, inspired by an observation of Lew Coburn, that this was equivalent to classifying certain $\mathrm{C}^{*}$-algebra extensions, namely, those where the ideal is the set of compact operators and the quotient is $C(X)$ for $X$ a compact subset of the plane. They were also interested in the more general case where $X$ is an arbitrary compact metric space, and our joint work eventually included a few results on still more general $\mathrm{C}^{*}$-algebra extensions.

When I arrived in Stony Brook, the most advanced case already solved was the case where $X$ is a circle. Ron knew that I had done some work on extensions of topological groups, using a version of group cohomology, and brought me to Stony Brook because he hoped that I could help with the project by using cohomological methods, but he started by leading me through the operator theoretic background that he needed. It turned out that my knowledge of topological group extensions didn't help, but I liked the project

\footnotetext{
${ }^{3}$ Larry Brown is a professor emeritus of mathematics at Purdue University. His email address is brown1@purdue. edu.
}

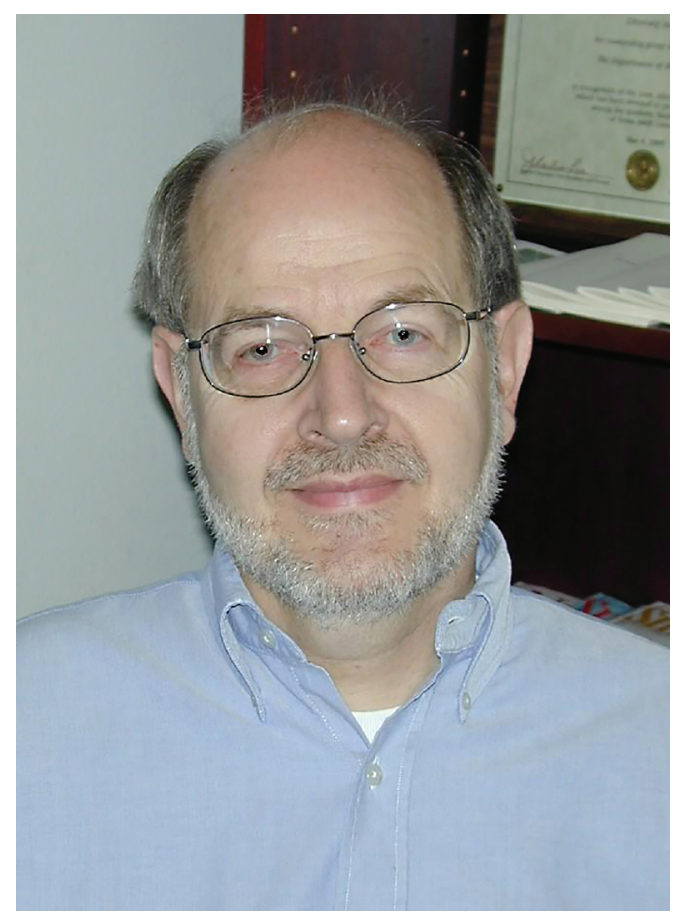

Figure 4. Douglas in his John R. Blocker Building office at Texas A\&M University. He remained active in research and graduate student mentorship until the time of his death.

and was happy to participate. The first bit of progress was to solve the case where $X$ is a figure eight. Our first exposition of our results, in volume 345 of the Springer Lecture Notes, will probably give the interested reader a reasonably good description of the way further progress was obtained.

\section{Lewis Coburn ${ }^{4}$}

Ron got his PhD from Pasquale Porcelli at Louisiana State University in 1962 and came to the University of Michigan as a Hildebrandt Instructor that fall. I was a graduate student at Michigan when Ron arrived. He wanted to teach a topics course on almost-periodic functions the following year and was actively recruiting students so that the course would run. I was a little curious, so I enrolled and learned a bit about the subject (as, I think, did Ron). A few years later, when we both were in the New York City area and had both done work in the periphery of the Atiyah-Singer theorem, we talked about doing an index theorem for Toeplitz operators with almost-periodic symbols on the real line as a possible interesting generalization of the known theory for continuous functions on the circle. The main difficulty was that the analogue of the winding number was the Bohr mean-motion, which takes on arbitrary real values. We learned from Izzy Singer about the (real-valued) Breuer index in a II 1 factor and then, with Singer and Dave Schaeffer, we put together what was, I believe, the first gen-

${ }^{4}$ Lewis A. Coburn is a professor of mathematics at State University of New York (SUNY) at Buffalo. His email address is 1coburn@buffa1o.edu. 
uinely real-valued index theorem and a precursor to Alain Connes' celebrated foliation index theorem.

Ron made a significant research impact on many aspects of operator theory. He was energetic and had a good sense of the interesting connections between operator theory and other areas of mathematics. On a personal note, I will miss his presence and express my sympathy to Bunny and his family.

\section{Alain Connes 5}

My encounter with the work of Ron Douglas goes back to a meeting in Rome in the winter of 1975. Iz Singer was giving lectures on index theory and operators in Hilbert space and discussing its connections to the work of L. Brown, R. Douglas, and P. Fillmore on extension of $\mathrm{C}^{*}$-algebras and $K$-homology. This encounter is one of the very few in my mathematical trajectory that actually made me alter my route, since it gave me the key concept for my later work by exhibiting how purely operator theoretic constructions could make geometry emerge from the quantum. The BDF theory was, with Atiyah's abstract elliptic operators, the birth of $K$-homology, which has played since then a vital role in the development of noncommutative geometry, leading to the concept of spectral geometry. Ron was a pioneer and fully deserves my admiration.

\section{Michael R. Douglas ${ }^{6}$}

As I reflect on my father's life, I realize in how many ways I followed in his footsteps. We were three children growing up in Ann Arbor and then Stony Brook, and our father showed us how attractive the academic life could be, bringing back gifts and photos from conferences in exotic countries and hosting dinner parties for visiting friends and colleagues from around the world. Just as appealing were the simple things: his home office filled with books, some of which he had written, or his freedom to come home early from work when we needed him, say, to help with a difficult project for school.

We made several long family trips that had a huge influence on me, especially a sabbatical semester in Newcastle-upon-Tyne in 1973 and a summer in France in 1970 that included a month in Les Houches. There, our mother would take us walking in the mountains while our father attended the well-known summer school that, that year, was on statistical mechanics and quantum field theory. Later as a young string theorist and mathematical physicist, I would often meet older colleagues, only to be told that it was not for the first time: They remembered me from when

\footnotetext{
${ }^{5}$ Alain Connes is a professor of mathematics at the Collège de France, IHES, and a distinguished professor at Ohio State University. His email address is alain@connes.org.

${ }^{6}$ Michael R. Douglas is a professor of physics and member of the Simons Center for Geometry and Physics at Stony Brook University. His email address is mdoug1as@scgp.stonybrook.edu.
}

I was little. This trip was also the very early seed of what would become a lifelong relationship with France. A year in 1990 visiting Volodya Kazakov and Edouard Brezin at the Laboratoire de Physique Theorique of the ENS in Paris, my collaboration with Alain Connes and Albert Schwarz at the IHES, and my many visits there as the Louis Michel chair all were in some way fulfilling that early attraction to French and European culture, to physics, and to mathematics.

Although I was fascinated by mathematics, I chose to major in theoretical physics in college, in part just to avoid following too closely in my father's footsteps. But my own research would turn out to have many points of contact with his, both by choice and by chance. After my early work on random matrix theory and the double scaling limit, my father suggested I talk to Dan Voiculescu, an old friend and colleague who had developed a framework called free probability theory. This contact led to a series of papers in the mid-1990s that introduced free probability into quantum field theory and condensed matter physics. But even more striking were the many mathematical developments that followed the famous work by the late Joe Polchinski on Dirichlet branes, including my collaboration with Connes and Schwarz, my work on Dirichlet branes and stability which led to Bridgeland stability, and most of my other work in the years around 2000. This could be the subject of an essay in itself, but for my purposes here, I will simply mention that Greg Moore pointed out at that time that there was a connection.

Another of the many mathematical ways to formalize the Dirichlet brane is that it is a class in the K-homology theory developed by Paul Baum and my father in 1982! So, I was destined to walk in his footsteps after all. Fortunately, he had chosen some very fruitful directions to walk in, and I am eternally grateful for that and for all that we shared together.

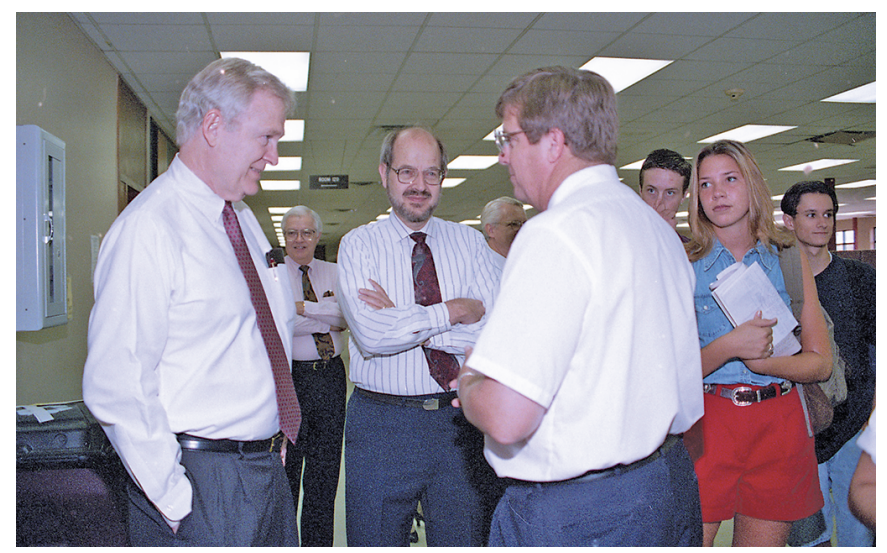

Figure 5. Douglas (center) touring the Texas A\&M University campus with then-President Dr. Ray M. Bowen (left) in 1996, shortly after arriving in College Station as provost and executive vice president. 


\section{Bill Helton ${ }^{7}$}

In August of 1968, my wife Joanne and I drove from Palo Alto to take my first job as an assistant professor at Stony Brook. Jim Simons had just arrived as the new chair of the math department that was housed in a utilitarian building with glazed tiles going halfway up the wall (which reminded me of a worn version of my high school). In August 1969, life picked up dramatically with the arrival of Ron Douglas, freshly poached from Michigan. Also in 1969, fresh out of grad school from Berkeley, came Roger Howe; then in 1971, a few years out of Harvard, came Larry Brown. Soon (I think) after Ron got to Stony Brook, he and Lew Coburn set up a seminar joint with Yeshiva University in the Bronx that met once every six weeks or so. I do not remember how often the New Yorkers came to Stony Brook, but traveling to the city was a formative event in my mathematical life because Ron was locked up with me on a train for several hours. I learned a huge amount of math from him on these trips, where I was immersed in his mathematical style. Here are a few observations about it:

- He loved to ask questions and encouraged all of us to do likewise in numerous bull sessions he promoted.

- He really liked simple conceptual proofs replacing complicated arguments. He had already had a lot of success with this in the subject of Toeplitz operators. It was not just that Ron wanted simple proofs-we all do-but Ron had huge faith that they existed for many topics.

- Ron had great admiration for topology. He thought it lived on the highest peak of mathematics. This was an exceptional viewpoint in the context of the Halmos era of American operator theory with great emphasis on complex variable techniques and the invariant subspace problem.

These traits and perspectives shone through in many conversations as soon as Ron arrived at Stony Brook, long before BDF. Ron was my main mathematical mentor, and I was so lucky in that regard. At grad school at Stanford, somehow I wound up working in general operator theory, while my advisor and others around had only modest interest in it; they loved mostly partial differential operators. Ron, on the other hand, was immersed in operator theory of all kinds and was an up-and-coming star. His enthusiasm, constant questions, and cogent explanations certainly propelled a beginner like me. Those were heady days at Stony Brook, on the ground floor of noncommutative geometry and several other subjects.

\footnotetext{
${ }^{7}$ J. William "Bill" Helton is a professor emeritus of mathematics at the University of California, San Diego. His email address is he1ton@ucsd.edu.
}

Operators at Stony Brook:

Primordial Noncommutative Geometry

In the first year Ron was at Stony Brook, I don't recall exactly what he was working on. I do remember learning a lot about Toeplitz operators and index arguments, and Ron being very happy when a homotopy argument was used. I was caught up in characterizing operators with a spectral representation on Sobolev spaces in the spirit of generalizing the usual spectral representation on $\mathrm{L}^{2}$-spaces.

Roger Howe also arrived that year. Though a group representor, operator-speak was no problem for Roger, and quickly Ron interested him in a new class of Toeplitz problems, Toeplitz operators on the quarter plane. Here the symbols are functions of two variables, very different from what people had been considering, and they wrote a seminal, far-reaching paper.

It was a little while before Ron converted Larry Brown to the cause. The question was close to one given by Halmos in his list of 10 problems: classify operators $M$ whose commutator with $M^{*}$ is a compact operator. Ron and Larry showed that $W$ is unitarily equivalent to $M$ plus some compact operator if and only if $M$ and $W$ have the same Fredholm index function. This required heavy estimates corresponding to chopped-up pieces of spectrum of $M$ (as I recall). Ron in one talk showed examples of unpleasantly complicated Toeplitz spectra and was proud that the BDF theorem handled that.

The Yeshiva Seminar Reenters the Story

For one meeting, Ron, Larry, and a visitor (possibly Fillmore) drove. I was not along. By the time they got back that night, they were no longer stuck with sets in the plane. They had good ideas of how their structure might generalize to higher dimensions, to lots of operators, and that serious homology was involved.

Life at Stony Brook was very exciting for the operator group on many counts. Roger and I became good friends as soon as he arrived in Stony Brook. He tried without much success to teach me some group representations, but after some time, in 1972-73, most of our time came to focus on formulas for traces of antisymmetrizations of operators (e.g., for two operators, commutators). He and I talked endlessly while playing horseshoes. This turned out to be the forerunner of cyclic-cohomology.

One moral of these stories is: Wasting time with your friends is not a waste of time.

\section{Ron and Adversity}

Ron was remarkably matter-of-fact in putting up with physical difficulties. The first snapshot I had of Ron's pluck is on the streets of the Bronx around 1970, walking near our Yeshiva seminar. Ron would walk-quickly, of coursedown the street, and he would realize it was time for his eye drops (glaucoma even back then). He pulled them out of his coat pocket while still walking briskly, held them above 
his head while still walking, and only stopped for a second as the drop hit. It was a real example to a squeamish guy who shuddered at eye drops every five years.

Another tale is Ron at the International Workshop on Operator Theory and its Applications (IWOTA) 2006 in Newcastle. While walking, he fell on the sidewalk and split the flesh on three fingers down to the bone. I was at my usual conference station, the coffee pot, when somebody came up and said Ron fell and is in the hospital. The fellow did not know Ron's condition, since the hospital would not let him in. I walked to the hospital about three blocks from the meeting, puffed my chest out, and spoke in a deep voice, "I am the vice president of a nearby conference, and one of my participants is in your hospital." They immediately whipped me back to a bed with Bunny sitting next to it. She looked jittery and was happy to see me, but Ron was nonchalant and wondered why I had left the conference. At some point, the doc came and began sewing Ron up while Ron yakked away, paying little attention to the whole thing. He kept telling me to quit bothering and head back to the conference, but I was not about to leave Bunny alone with this. Eventually the stitching was done, Bunny and I relaxed some, and, of course, Ron just kept on entertaining us.

All of us who knew Ron will miss him personally, but we will never forget his example.

\section{Roger Howe}

Looking back, I see that Ron Douglas was the dominant influence for my work in operator theory. He also was the central player in the most stimulating and enjoyable mathematical interaction I have enjoyed.

Ron introduced me to Toeplitz operators before we even met. When I was a graduate student at Berkeley, Ron gave a guest lecture in one of my courses. He spoke from his in-progress text/monograph (now classic) Banach Algebra Techniques in Operator Theory, where Toeplitz operators provide one of the main examples.

I next encountered, and truly met, Ron at Stony Brook, where we had both arrived by independent routes as part of the group Jim Simons assembled to put its mathematics department on the map.

The operator theory group at Stony Brook was remarkably strong, with Ron and Joel Pincus being the most senior, then Bill Helton, and a little later Larry Brown. Although I thought of my main research path as group representation theory, the lack of a colleague to talk with about representations, coupled with the abundance of talent and interest in operator theory, drew me into that group. Another factor that promoted interaction was the assignment of the mathematics department to overflow space on the edge of campus-a one-story building with wide hallways, where everyone's office was a short stroll down the hall. This led to frequent, fertile conversations.

Ron was still studying Toeplitz operators, with emphasis on the structure of the algebra they generate. A key fact here is that the commutator of any two Toeplitz operators with continuous symbol is compact, so that the $\mathrm{C}^{*}$-algebra Toep generated by the Toeplitz operators would form an extension

$$
0 \rightarrow \mathrm{K} \rightarrow \text { Toep } \rightarrow \mathrm{C}(\mathrm{T}) \rightarrow 0,
$$

where $\mathrm{K}$ indicates the algebra of all compact operators on a Hilbert space, and C(T) denotes the algebra of continuous complex-valued functions on the unit circle.

It was always fun to discuss mathematics with Ron. His way of doing math was to make connections, to clarify ideas, to identify key issues. He rarely if ever got bogged down in details. He knew a lot, but he was always asking questions and looking for new relationships. My first paper on operator theory was a joint paper with Ron, on the analogue of Toeplitz operators on the quarter-plane, and described the structure of the $\mathrm{C}^{*}$-algebra generated by such operators. It might be seen as an early signal of Ron's continuing interest in multidimensional operator theory.

The spring term of 1973 was especially memorable. Joel Pincus had been studying singular integral operators on the line, which are closely related to Toeplitz operators. He had defined a function, the principal function, that provided a complete unitary invariant for an appropriate class of such operators. Both types of operators provided examples of operators $T$ for which the "self-commutator" $\left[T, T^{*}\right]$ (where $T^{*}$ indicates the Hilbert space adjoint of $T$ ) is trace class (and in many interesting examples, finite-dimensional). In 1972-73, Bill Helton and I were stimulated by this work, and Bill had the idea that studying the bilinear form defined by taking the trace of commutators in the * ${ }^{*}$-algebra generated by the operator could produce interesting results. 
Pursuing this approach, we soon understood that it gave rise in a natural way to Pincus's principal function and, furthermore, had natural connections with homology and index theory.

At the same time, Ron and Larry Brown, also with Peter Fillmore of Dalhousie University, were pursuing the problem of finding extensions analogous to the Toeplitz operators, but with $\mathrm{T}$ replaced by an arbitrary compact subset of the plane. The four of us had almost daily discussions, sharing progress, which came quite rapidly with both projects. Ron was effectively our convener, providing background (Halmos's program, Weyl's result on compact perturbation of self-adjoint operators, Putnam's results on hyponormal operators, Atiyah's views on index theory) as well as his own insights.

Both projects resolved successfully in spring 1973, and the results were celebrated and disseminated with a conference organized by Peter Fillmore at Dalhousie in April 1973. I do not remember why, but I was unable to attend. I have always regretted missing it.

The Brown-Douglas-Fillmore paper had a major impact on the study of $\mathrm{C}^{*}$-algebras and essentially gave rise to new variants of $K$-theory and especially $K$-homology. Bill and I liked to think of our paper as a "differential geometry" version of the essentially topological BDF paper. Both papers apparently influenced Alain Connes, who cites them together in his 1985 Publications de l'I.H.E.S. paper that started the still active field of noncommutative geometry. Spring 1973 in Stony Brook, with its intensely interactive and collaborative atmosphere, presided over by Ron, remains a high point in my mathematical life.

\section{Jerry Kaminker 8}

My wife and I got to know Ron and Bunny well during the 1984-85 year at MSRI, and they were among our closest friends ever since. We took many trips with them, often tied to math. Ron's mathematical strengths and contributions were remarkable. Perhaps the most significant were his efforts to connect operator theory to other areas of mathematics, such as geometry, topology, and algebraic geometry. This would enrich both topics. Two striking examples are his work with Brown and Fillmore and his work with Baum and Taylor. Both of these led to a refined form of the Atiyah-Singer index theorem expressed in terms of $K$-homology and provided the foundations for the work of Kasparov and eventually Connes's development of noncommutative geometry. A second direction was Ron's work with Cowen classifying certain bounded operators in terms of the geometry of associated Hermitian complex vector bundles. This led in various ways to new approaches to operator theoretic problems. It's remarkable how well

\footnotetext{
${ }^{8}$ Jerry Kaminker is a professor emeritus of mathematical sciences at Indiana University-Purdue University Indianapolis (IUPUI). His email address is kaminker@iupui.edu.
}

the BDF theory holds up forty-five years later. There were many other instances of connections like these which Ron initiated and developed. He had many students and postdocs who went on to produce first-rate work in this spirit.

Ron and I started to collaborate at MSRI in a joint project with Steve Hurder. While the fact that the AtiyahSinger index theorem established a precise connection between analysis and topology was understood, whether that matchup extended to invariants more refined than the index (i.e., which depend on more than the principal symbol) was less clear. This type of question was behind our work relating cyclic cocycles and the eta invariant and was a theme that continued over the years in work involving families of self-adjoint elliptic operators and, in joint work with Xiang Tang, studying analytic versions of differential $K$-homology. Again, it was Ron's ability to reason in various fields, sketch out a plan, and then go home and work it out that drove our work. I remember another collaborator of Ron's who said that Ron would tell him things that sounded far-fetched but in virtually every case turned out to be correct. In general, I found that to be true also.

Ron was fairly serious and careful in life, so there aren't really many ridiculous anecdotes to relate. But he did enjoy a good time. He and Bunny loved to go to bars with piano players. They did this in Stony Brook at the Three Village Inn and in College Station at Veritas. They always became good friends with the musicians.

Doing things with the Douglases usually involved a sequence of several events, any one of which would have taken us a whole day. Once he and Bunny took us around New York, which we didn't know well. We went to the Metropolitan Museum, Nathan's Hot Dogs, Sardi's for a drink, a Broadway play, dinner in the Village, and then jazz in the Village. After this, ordinary excursions seemed trivial.

Ron believed strongly in institutions and their potential for improving society. He was a very talented administrator,

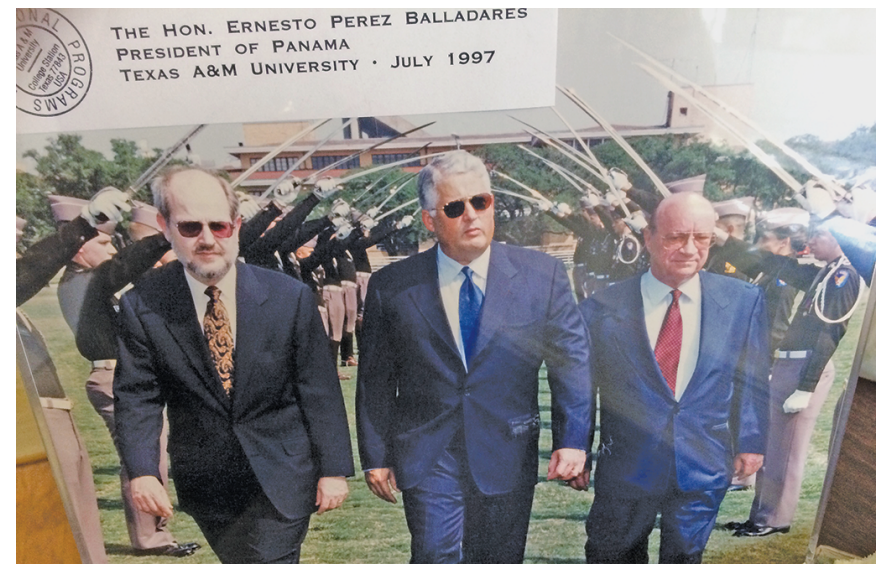

Figure 7. As Texas A\&M's provost and executive vice president, Douglas (left) helped vastly expand the university's international presence, from hosting visiting presidents and dignitaries to founding a new branch campus in Qatar. 


\section{MEMORIAL TRIBUTE}

and the organizations he worked with inevitably became stronger. His interest and involvement with education lasted his entire career. However, he always continued working on mathematics throughout these activities.

In all this, Ron's priorities were, in order, his family, mathematics, and education. He was unique in his mathematical vision, and his ideas and work will continue to flourish.

\section{Albert C. Lewis 9}

Ron joined a group put together by Harry Lucas Jr. and the Educational Advancement Foundation (EAF) in 2003 to develop centers of inquiry-based learning (IBL) at five universities. He agreed to be the coordinator of the project, whose first task at that point was to review the proposals submitted from Harvard University, University of Chicago, University of Michigan, University of Texas at Austin, and University of California at Santa Barbara. This likely reminded him of his work from 1990 as chair of the National Research Council committee preparing a report on doctoral study in mathematics [4] that similarly involved site visits and detailed analyses of programs at ten representative universities. Though pedagogy was one aspect of this earlier study, the focus of EAF on IBL would have appealed to Ron, given his own educational pedigree:

A little more than 50 years ago, I entered a classroom at the Illinois Institute of Technology (IIT), where I was a freshman, and had an experience that changed my life. The professor, Pasquale Porcelli, was teaching calculus using an inquiry-based approach I learned later was called the Moore Method. [5]

At the University of Texas at Austin, R. L. Moore and H. S. Wall, Porcelli's professor there, inspired many students in a similar way. Harry Lucas likewise did. Despite continuing in the family oil business instead of pursuing a career in mathematics, Lucas founded EAF with the goal in mind of insuring that the "Texas method" of teaching did not die out. At the time, a common response of outside potential funders was to ask what the evidence was showing that this method is really effective. In answer, a large-scale assessment project of many of the programs at the centers was sponsored, and Ron was the liaison between the foundation and the project. Run by the University of Colorado Ethnography \& Evaluation Research group, the project started in 2007 and took four years to collect and evaluate data based on observations and records of IBL and non-IBL classes and is the largest one to date devoted to undergraduate teaching methods in mathematics classes. The final report is now a standard reference in the field and a primary source of evidence that, among other points, IBL

${ }^{9}$ Albert C. Lewis is a consultant with The Legacy of R. L. Moore Project. His email address is alewis@edu-adv-foundation.org.

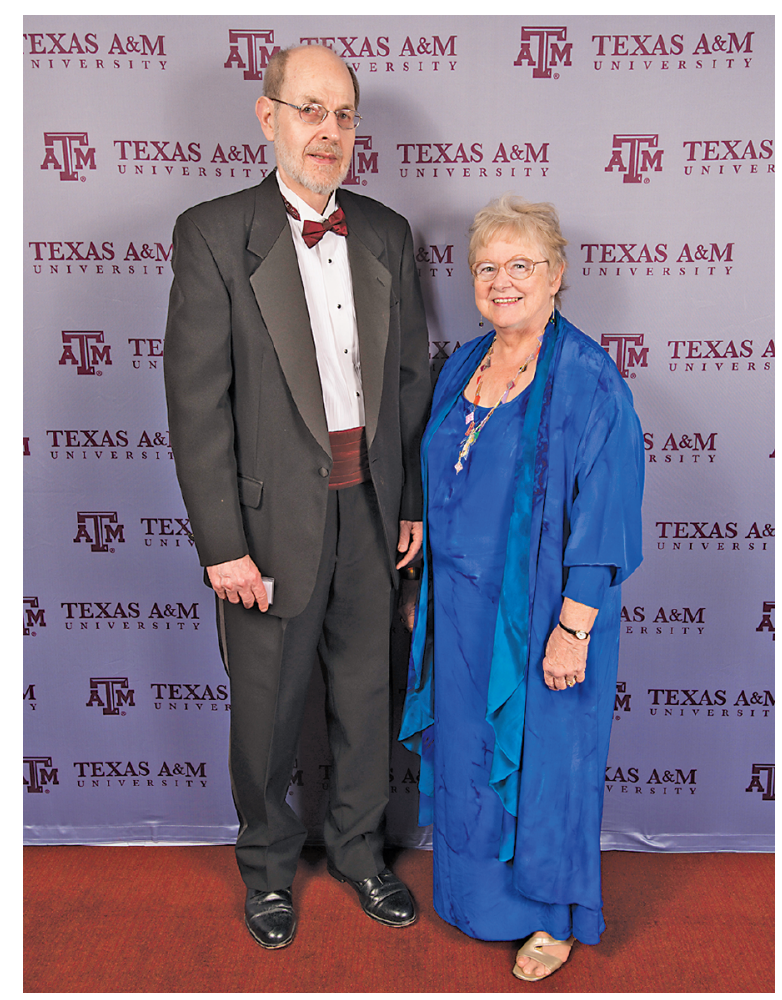

Figure 8. Ron and Bunny Douglas at the 2013 Texas A\&M University Institute for Advanced Study (TIAS) Gala.

methods support positive learning outcomes in various groups of students, with an especially striking difference, compared with non-IBL methods, for students who are not already high achievers in mathematics and for women [6].

Elected a trustee of EAF in 2008, Ron was instrumental in garnering support from funders and in promoting outreach programs for instructors. That year he suggested that an Academy of IBL could be a networking vehicle for interested practitioners. The idea was well received when it was floated at the EAF-sponsored 12th Annual Legacy of R. L. Moore Conference in 2008, and he helped to plot its initial structure. He was a regular attendee at these conferences, which, under the more general "IBL Conference" rubric, continue as a major gathering for introducing and discussing all aspects of active learning practices. Many of the same ideas that motivated the academy idea independently gave rise to the IBL Special Interest Group of the MAA, whose charter proposal was drafted by a younger generation of participants at the 18th Annual Conference in 2015.

Another issue he addressed was the need to critically compare the increasingly diverse range of possibilities open to a teacher as alternatives to supplement or replace the traditional lecture method. Ron organized a symposium in 2016, bringing together experts in education and economics research methods with active learning mathematics practitioners and departmental leaders to review current evaluation efforts. The results of the symposium, supported 
by the Sloan Foundation, National Science Foundation, and EAF, were discussed at a follow-up session at the Joint Mathematics Meetings and are available in video and print at www . math . tamu . edu/ rdouglas/materials/index . htm 1

In 2017, Ron agreed to join the board of directors of a new foundation, the Initiative for Mathematics Learning by Inquiry (MLI). As a public charity, MLI is intended to nationally extend many of the programs initiated by the $\mathrm{EAF}$, a private foundation.

In all of his nonprofit roles, Ron contributed greatly to the huge growth in the interest of the mathematics research and teaching community in pedagogies of the kind that so influenced him.

\section{Gadadhar Misra ${ }^{10}$}

I still can't believe that Ron is no more. I had first heard of him at Sambalpur University, in the year 1977, from one of his former students, Dr. Swadhin Pattanayk, who taught a topics course to our class from the book Banach Algebra Techniques in Operator Theory, written by R. G. Douglas [2]. This book was unlike any other book on functional analysis that we had seen at that time. In a way, it set the tone for several such books that appeared later. In spite of the advanced nature of the topics covered in this book, some of us found it very instructive, and my mind was made up to work with Professor Douglas if I should ever get a chance.

I first met Professor Douglas on September 13, 1979. He was the director of graduate studies in the mathematics department of SUNY, Stony Brook. I had just arrived to begin my work for a PhD. I remember telling him at the very first meeting, in a somewhat awkward manner, that I had come to work with him. He smiled and said, "You don't have to worry about all that right now." I didn't quite understand what he meant at that time. Finally, when I was ready to begin research, he said, "I will have very little time for you. Maybe you should consider working with someone else." Afraid that he may not take me as a student, I nervously assured him that I will not take much of his time. When he accepted me as a student, I was thrilled and filled with joy. Because of his several administrative duties, I did not get the opportunity to talk to him very much when I was in graduate school. Nonetheless, he did point me in the direction of finding inequalities for the curvature invariant of a Fredholm operator possessing an open set $\Omega$ of eigenvalues and of index -1 . Abstracting these properties, he, along with M. J. Cowen, had introduced the important class of operators $B_{n}(\Omega)$ earlier in the very substantial paper [7]. The operators in this class are now known as the Cowen-Douglas operators, and they have been studied continuously and vigorously to this date without showing any sign of slowing down.

\footnotetext{
${ }^{10}$ Gadadhar Misra is a professor of mathematics at the Indian Institute of Science in Bangalore. His email address is gm@math. i isc. ernet. in.
}

As if to make up for the lack of our interaction when I was a graduate student, he invited me to join him in carrying forward his program on Hilbert modules described in the book [8]. After I returned to India in 1985, I made several trips to Stony Brook during the summers, starting from the summer of 1986, to work on this topic. It was a matter of great pride for me when he was able to visit India for the first time during the winter of 1996 just before moving to Texas A\&M as the provost. Indeed, if I recall correctly, he came to Bangalore from Stony Brook but returned to College Station. This trip was followed by several others to India. During each one of these trips, he would lecture extensively and talk to a number of young students. The two of us had organized a special session on multivariate operator theory in the AMS-IMS annual meeting. This was held at the Indian Institute of Science, Bangalore, in December of 2003. In a postscript to the hugely influential paper [9] containing the main ingredients for what is called the Arveson-Douglas conjecture, he says, "This research was begun during a visit to India supported in part by the DST-NSF S\&T Cooperation Program. During conferences in Chennai and Bangalore, the author had the opportunity to speak with $\mathrm{W}$. B. Arveson about his results. The author would like to acknowledge that these conversations prompted this work."

He had an uncanny knack for asking what might appear to be simple questions that, more often than not, have resulted in deep and new insights. Let me give a couple examples.

The class introduced in [7] consists of operators acting on some Hilbert space $H$ possessing an open set $\Omega \subseteq$ C of eigenvalues of (constant) multiplicity 1 and characterized by the existence of a holomorphic map $\gamma: \Omega \rightarrow H$ such that $\gamma(w)$ is an eigenvector with eigenvalue $w \in \Omega$. One of the main features of the operator $T$ in this class is that the curvature

$$
K_{T}(w):=-\partial \partial \log \left\|\gamma_{T}(w)\right\|^{2}
$$

of the holomorphic Hermitian line bundle $E_{T}$ determined by the holomorphic map $\gamma_{T}$ equipped with the Hermitian structure $\left\|\gamma_{T}(w)\right\|^{2}$ is a complete unitary invariant for the operator $T$. It is easy to see that if $T$ is a contraction in the Cowen-Douglas class of the unit disc D, then $K_{T}(w) \leq$ $K_{S}{ }^{*}(w)$, where $S^{*}$ is the backward unilateral shift acting on $l^{2}$. Choosing a holomorphic frame $\gamma_{S}{ }^{*}$, say $\gamma_{S}{ }^{*}(w)=(1, w$, $\left.w^{2}, \ldots\right)$, it follows that $\left\|\gamma_{S}{ }^{*}(w)\right\|^{2}=\left(1-|w|^{2}\right)^{-1}$ and that $K_{S}{ }^{*}(w)=-\left(1-|w|^{2}\right)^{-2}, w \in \mathrm{D}$. Thus the operator $S^{*}$ is an extremal operator in the class of all contractive CowenDouglas operators. A very simple question that Ron asked many years ago was, if the curvature $K_{T}$ of a contraction $T$ achieves equality in this inequality even at just one point, does it follow that $T$ must be unitarily equivalent to $S^{*}$ ? Once the question is raised it is easy to see that the answer 
is no, in general. However, if $T$ is homogeneous, namely, $U_{\wp} T U_{\wp}=\wp(T)$ for each biholomorphic automorphism $\wp$ of the unit disc and some unitary $U_{\wp}$, then the answer is yes. Of course, it is then natural to ask what are all the homogeneous operators. Finding these has been a very rewarding experience. In the process, one discovers many interesting relationships between complex geometry, representation theory of Lie groups, and operator theory. Also, it is natural to replace the unit disc by a more general domain either in $\mathrm{C}$ or even in $\mathrm{C}^{n}$ and make up similar questions. Finding answers to these is not entirely trivial and almost always involves adapting techniques from other related areas and having to find new ones.

Another topic, among many others, that was very close to his heart is the study of Hilbert modules, which he introduced in the mid-1980s, based on his lectures at Sichuan University. A Hilbert module is simply a Hilbert space together with an action of a function algebra. In all the familiar examples, one has a natural action, given by pointwise multiplication, of the ring of polynomials or the rational functions. What he called a Hilbert module required this action to be continuous in both variables. One of the first observations he made was that all the submodules of the Hardy module are isomorphic to the Hardy module; that is, there exists an intertwining unitary module map between them. This immediately gives an alternative proof of Beurling's theorem, describing all the submodules of the Hardy module. The point of this new proof was to ask what happens in the multivariate case. For instance, if one considers the Hardy module over the polydisc algebra, the situation is much more complicated. This new approach, however, explains why attempts to prove a theorem like that of Beurling had failed in that case. Also, it becomes apparent that finding the moduli space for the isomorphism classes of submodules of a Hilbert module is a very interesting problem. What Ron had observed is that the moduli space is a singleton for the Hardy module in one variable. It is surprising that while the study of isomorphism classes of quotient modules can be seen to be the familiar problem of the Sz-Nagy-Foiass model theory, a similar question involving submodules had to wait for the notion of Hilbert modules to be introduced.

The last time I met Ron was at the Workshop on Analytic Hilbert Modules, held at the Yau Mathematical Sciences Center in May 2017. I was there along with several PhD students and young researchers from India. All of them were clearly very happy to have the opportunity to talk to Ron in person. I hardly imagined that it would be our last meeting. Now, all that is left is the memory of those few days that we spent together.

All of us here in India and others around the world who have benefited greatly from his lectures, books, and clear expositions will miss him very much in the years to come. I, for one, having had the chance to work with him and having come to depend on him over the past several years, will take a very long time before I can find my feet again.

\section{Emil Straube ${ }^{11}$}

I first learned of Ron Douglas around 1980 as a PhD student at ETH Zurich through his wonderful books on Banach algebra techniques. I don't recall the details, but presumably this contact arose through my writing of a master's thesis (Diplomarbeit) on certain Toeplitz operators on the half plane. I only met Ron in person many years later, after he came to Texas A\&M as executive vice president and provost in 1996.

During this initial period, our contact was mostly through his graduate students, whom he would occasionally send to me with a question. Already in my $\mathrm{PhD}$ thesis, I had started to work in several complex variables, but there is of course plenty of overlap, such as spaces of analytic functions on various classes of domains, or operators like the Bergman and Szegö projections, and, not least, Toeplitz and Hankel operators, as well as various algebras of operators in several variables. I remember being impressed with how Ron kept up his research throughout his administrative appointments.

This impression was reinforced when Ron's tenure as provost ended, and he came to the department. Clearly, he had not missed a beat. In the department, in addition to doing some of his best work, Ron quickly grew into the role of elder statesman. This became even more clear to me after I was appointed department head in 2011. For many years, Ron chaired the departmental Committee of Distinguished Professors, as well as the analogous committee at the college level. He was extremely helpful in both these roles, but also in many other ways, and I benefited greatly from his experience and wise counsel. Sometimes, Ron would stop by the office to discuss a question about this or that ideal of analytic functions in, say, a strictly pseudoconvex domain, thereby rescuing me from the doldrums of administration for an hour. I don't recall being of much help, but I think we both enjoyed these conversations.

Apart from his mathematics and his administrative acumen, two things particularly impressed me about Ron. The first is his undaunted persistence in the face of adversity in his last years, when his health had started to decline. He simply would not give in until the end. The second is his sense of duty as a scholar. This included his commitment to his students. When I visited him a few days before he passed away, he was very concerned about his last graduate student, who was supposed to graduate that summer. Although he could barely speak, and only with great difficulty,

\footnotetext{
${ }^{11}$ Emil J. Straube is a professor of mathematics and former head of the Department of Mathematics (2011-2019) at Texas A\&M University. His email address is straube@math.tamu.edu.
} 
he wanted to know that we made sure that she would be okay (she was, thanks to my colleague Guoliang Yu).

A few years ago, two of Ron's friends and colleagues here at Texas A\&M, Ciprian Foiaş and Carl Pearcy, suggested to the department that it was time to honor Ron with an annual lecture series named after him. Indeed, it was, and they made this easy with very generous donations to start an endowment. This spring, we concluded the fifth installment of the Douglas Lectures with three presentations by Vaughan Jones. We still have to get used to Ron not being present at the lectures.

Ron Douglas was a true scholar, a wonderful colleague, and a good friend to many. We will miss him.

\section{Xiang Tang ${ }^{12}$}

My collaboration with Ron Douglas started around the time Guoliang Yu moved to Texas A\&M in 2012. At that time, Ron was thinking about the Arveson-Douglas conjecture. He talked to Guoliang and me about a very interesting index theory question regarding identifying the $\mathrm{K}$-homology class associated to an essentially normal Hilbert module. The three of us worked together on this problem over the past five years. Ron liked discussion on the phone. During our many phone conversations, I was impressed by Ron's broad knowledge and long vision of mathematics.

As I was a PhD student at UC Berkeley and also an academic grandson of Shiing-Sheng Chern, Ron once told me a story about an incident involving the Mathematical Sciences Research Institute and Chern. Ron co-chaired the National Science Foundation committee on selecting the location for MSRI. During his visit to Berkeley, Ron was particularly impressed by Chern as both a great mathematician and excellent administrator. As a part of the negotiation,

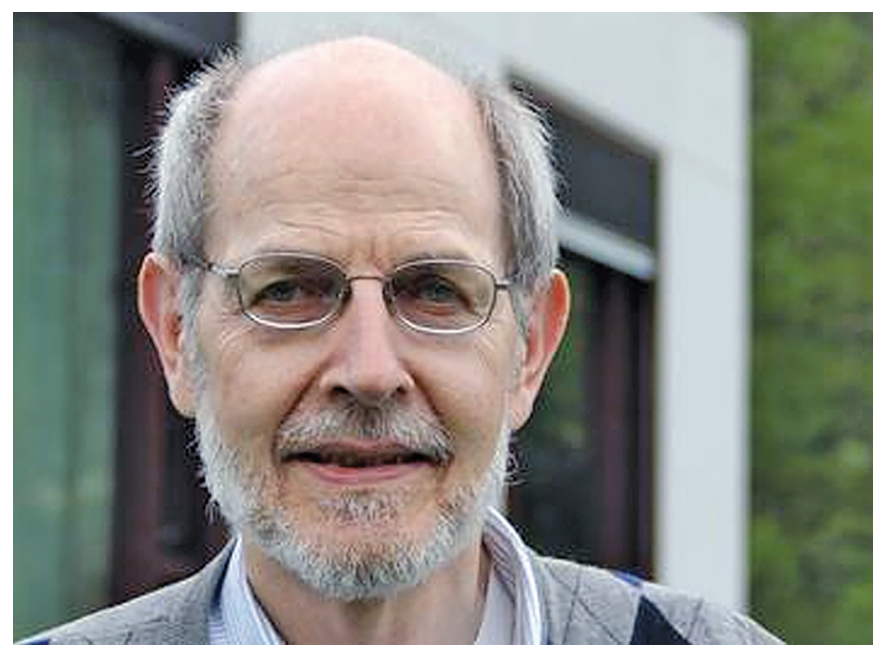

Figure 9. Douglas in Oberwolfach, 2014.

\footnotetext{
${ }^{12}$ Xiang Tang is a professor of mathematics at the University of Washington, St. Louis. His email address is xtang@math. wust 1. edu.
}

the committee requested that Chern serve as the founding director of the MSRI, which turned out to be a great success.

\section{Guoliang Yu}

I first met Ron when he was giving a lecture series at $\mathrm{Si}$ chuan University in 1985 at the invitation of Professor Shunhua Sun. One day, I visited him at the International Guest House with several other students. I asked him the question of how one can define the Fredholm index intrinsically. He gave me a one-hour lesson on how you would do this, teaching me $K$-theory along the way. I was struck by his passion for mathematics and his generosity with students. He continued to share with me his bountiful knowledge and insights of mathematics when I became his PhD student in 1987 at Stony Brook. Ron was the dean of the College of Physical Sciences and Mathematics. Despite how busy he was with this, he still always made the time to meet me regularly. Each time we met, he would describe to me the big picture of the topic under discussion. I benefited enormously from his vision of mathematics and was always inspired by his insightful views. After I finished my $\mathrm{PhD}$, I would still call him up to ask him for advice on my career options. In 2012, I took a position at Texas A\&M. We met on a weekly basis to talk about mathematics, politics, and life in general. Ron had the special ability to look at things from a distance and see the essence. Ron was a wonderful teacher, mentor, and friend to me. I miss him dearly.

\section{References}

[1] Brown L, Douglas R, Fillmore P. Extensions of $C^{*}$-algebras and K-homology, Ann. of Math. (2), 105 (1977), no. 2, 265-324. MR0458196

[2] Douglas R. Banach algebra techniques in operator theory, Pure Appl. Math., Vol. 49. Academic Press, New York-London, 1972. MR0361893

[3] Douglas R. C*-algebras extensions and K-homology, Ann. of Math. Stud., 95. Princeton University Press, Princeton, NJ; University of Tokyo Press, Tokyo, 1980. MR0571362

[4] National Research Council (US). Committee on Doctoral and Postdoctoral Study in the United States., Educating mathematical scientists: doctoral study and the postdoctoral experience in the United States. Washington, DC: National Academy Press, 1992.

[5] Douglas R. Inquiry-Based Learning: Yesterday and Today, Notices Amer. Math. Soc., 59 (2012), 668-669.

[6] Laursen S, Hassi ML, Kogan M, Hunter AB, Weston T. Evaluation of the IBL Mathematics Project: Student and Instructor Outcomes of Inquiry-Based Learning in College Mathematics. (Report to the Educational Advancement Foundation and the IBL Mathematics Centers). University of Colorado Boulder, Ethnography \& Evaluation Research, Assessment \& Evaluation Center for Inquiry-Based Learning in Mathematics, Boulder, CO, 2011.https://www.colorado.edu/eer /research/steminquiry.htm7

[7] Cowen M and Douglas R. Complex geometry and operator theory, Acta Math., 141 (1978), 187-261. MR0501368

[8] Douglas R and Paulsen V. Hilbert modules over function algebras, Pitman Research Notes in Mathematics Series, 217, 1989. MR1028546 


\section{MEMORIAL TRIBUTE}

[9] Douglas R. Essentially reductive Hilbert modules, J. Operator Theory, 55 (2006), 117-133.MR2212024

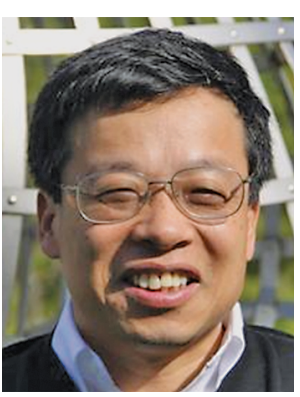

Guoliang Yu

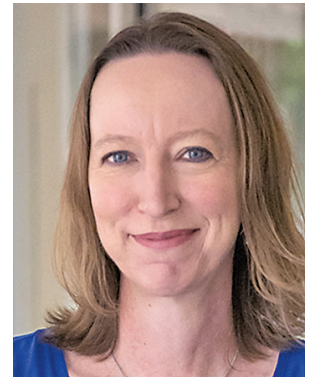

Shana Hutchins

Credits

Figure 1 is courtesy of Texas A\&M University.

Figures 2, 6, and 7 are courtesy of the Douglas family.

Figure 3 is courtesy of Guoliang Yu.

Figure 4 and Hutchins author photo are courtesy of the College of Science, Texas A\&M University.

Figure 5 is courtesy of Cushing Memorial Library and Archives, Texas A\&M University.

Figure 8 is courtesy of Kim Topp, Division of Research, Texas A\&M University.

Figure 9 is from the Archives of the Mathematisches Forschungsinstitut Oberwolfach, $\odot$ Ivonne Vetter.

Howe author photo is courtesy of Roger Howe.

Yu author photo is from the Archives of the Mathematisches Forschungsinstitut Oberwolfach, ${ }^{\oplus}$ Petra Lein.

\section{0 HOW/IOW Pall for Entiles Forvany 13-17, 2020

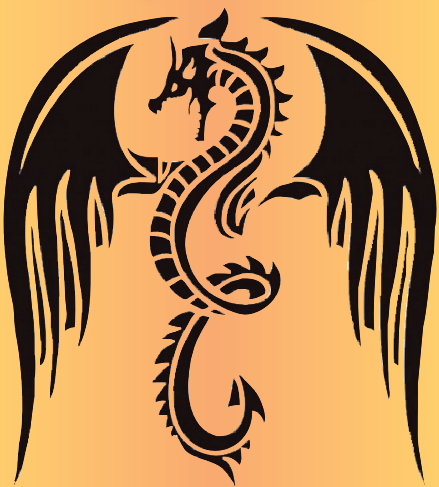 \\ WWWHembontiestroom

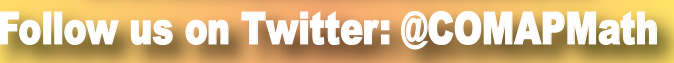

COMAP's Mathematical Contest in Modeling (MCM) and The Interdisciplinary Contest in Modeling (ICM) are international contests designed to provide students with the opportunity to work as team members to engage in and improve their modeling, problem solving, and writing skills. Teams from around the world apply mathematics to model and develop a solution to a real-world problem.

Teams will have a 4-day window in which to download and choose their problem, complete their modeling solution, and electronically submit their solution document to COMAP for centralized judging. Each team may choose any one of the six problem choices.

MCM Problem A (continuous)

MCM Problem B (discrete)

MCM Problem C (data insights)

ICM Problem D (operations research/network science)

ICM Problem E (environmental science)

ICM Problem F (policy)

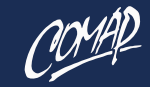

www.comap.com 